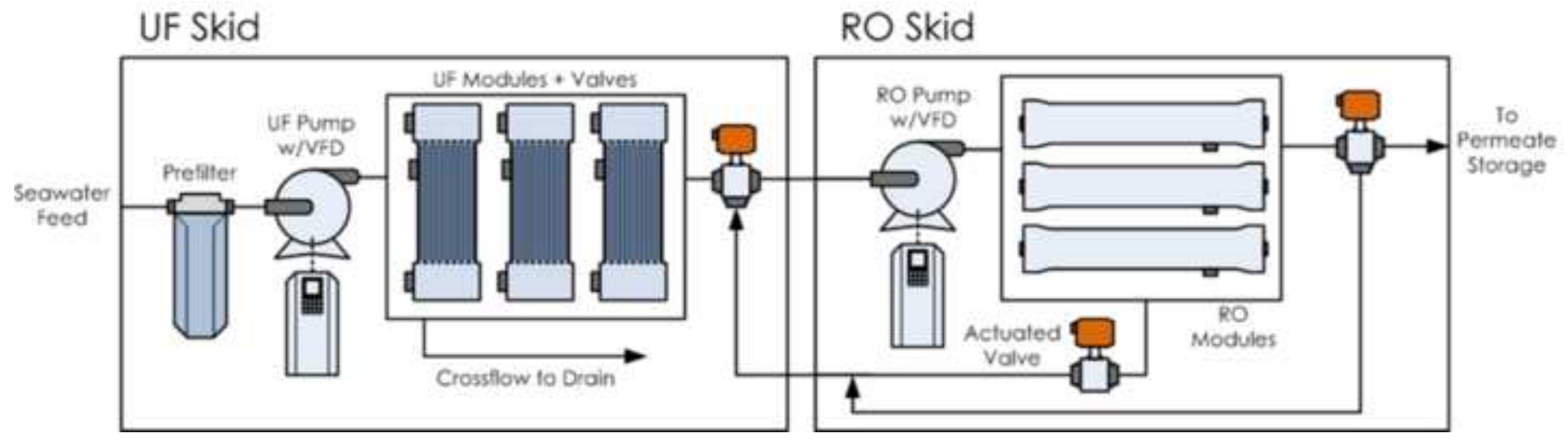




\title{
Novel Design and Operational Control of Integrated Ultrafiltration - Reverse Osmosis System with RO Concentrate Backwash
}

\author{
Larry X. Gao ${ }^{*}$, Anditya Rahardianto ${ }^{*}$, Han $G u^{*}$, \\ Panagiotis D. Christofides ${ }^{+, \dot{t}}$, and Yoram Cohen ${ }^{*, t}$
}

${ }^{+}$Co-Corresponding Author, Tel.: +1 (310) 794-1015, E-mail: pdc@ seas.ucla.edu

* Co-Corresponding Author, Tel.: +1 (310) 825-8766, E-mail: yoram@ucla.edu

* Water Technology Research Center, Department of Chemical and Biomolecular Engineering, University of California, Los Angeles, California 90095-1592, United States 


\begin{abstract}
A novel design for a reverse osmosis (RO) desalination system directly integrated with an ultrafiltration (UF) pre-treatment unit was developed. The integration involves direct RO feed from the UF filtrate and UF backwash using the RO concentrate. This alignment reduces overall plant footprint, while the use of RO concentrate for UF backwash allows $100 \%$ UF recovery and implementation of flexible backwash strategies. The present system design utilizes a control scheme, whereby RO productivity can be prescribed independently of the UF system which selfadjusts to provide the RO system with its required feed flow rate at the specified RO pump inlet pressure. UF backwash, achieved via direct RO concentrate flow from the RO system provided a continuous flow for sequential UF backwash which was additionally integrated with pulse backwash using a hydraulic accumulator. Seawater desalination field studies with a UF-RO pilot system of 12,000 gallons/day permeate production capacity successfully demonstrated the advantage of RO concentrate UF backwash that was triggered based on a membrane resistance threshold. The above self-adaptive UF backwash strategy significantly extended the projected UF operation period (by a factor of nine) to the threshold of required chemical cleaning.
\end{abstract}

Keywords: Field Study, Reverse Osmosis Desalination, Seawater Desalination, Ultrafiltration, Process Control, Pulse backwash, RO Concentrate Backwash, UF-RO Integration, Process Intensification 


\section{Introduction}

Over the past two decades, reverse osmosis (RO) has emerged as a leading method for seawater and brackish water desalination, as well as for various water reuse and decontamination applications $[1,2]$. However, membrane fouling remains a major challenge for robust operation of RO plants [1-5]. Membrane fouling increases the overall resistance to water permeation across membranes and thus higher required applied pressure for a given water production level, which leads to increased operational costs and, eventually, reduced membrane lifespan. Therefore, effective pre-treatment of RO feed water (for complete or partial removal of potential foulants such as particulates, colloids, and organic matter) is often required to ensure robust long-term operation of RO plants $[4,6]$. In this regard, ultrafiltration (UF) has been shown to produce consistently higher quality filtrate water compared to conventional feed pre-treatment options (e.g. sand filters, cartridge filters), leading to longer lifespan of downstream RO membranes [613]. The use of UF for RO feed pretreatment is particularly attractive since UF membrane water permeability, which declines due to fouling, can be recovered with effective periodic backwashing (reversing the flow direction) [6-9] and routine chemical cleaning-in-place (CIP) [13-15].

Given the scalability of membrane technology, UF-RO systems are suitable for medium- and large-scale municipal and industrial plants, as well as small-scale water treatment applications for remote communities, emergency response, and shipboard deployments [13, 16, 17]. Integration of UF with RO is practiced in a variety of industrial and municipal applications $[6,9$, 13, 18-20]. However, conventional UF-RO systems typically utilize UF filtrate for periodic UF backwash, necessitating the use of intermediate tanks to store UF backwash water (during periods in between backwash cycles) and for assuring continuous delivery of UF filtered RO feed (Fig. 1) [6, 9-13, 18, 19]. A dedicated UF backwash pump is typically needed to drive UF 
backwash, while a separate low-pressure RO booster pump may be needed to re-pressurize UF filtrate to prevent cavitation in downstream the high-pressure RO feed pump (Fig. 1). In addition to added maintenance and cleaning requirements $[9,21-23]$, intermediate UF filtrate tanks and the associated pumps present a system design challenge when space is limited or portability is important. More importantly, operational flexibility of UF backwashing using UF filtrate may be constrained by the UF filtrate tank capacity, coupled with the need to maintain continuous RO feed flow. As consequence, a fixed UF backwash strategy (whereby backwash frequency, duration, and intensity are fixed) is often practiced in conventional UF operations. Such passive strategy may not be optimal for robust UF-RO plant operation as UF feed water quality and fouling propensity can vary significantly with time in the short term, as well as seasonally [5, 9, 24]. When UF filtrate is utilized for UF backwash, implementation of a variable UF backwash strategy (i.e., backwash frequency, duration, and intensity to adapt to changing feed water quality) may necessitate concurrent variation or reduction of UF productivity (e.g. for subsequent RO treatment) in order to achieve the required backwash effectiveness while still meeting the constraint imposed by UF filtrate tank capacity [24]. Frequent changes in RO feed flow is undesirable as it necessitates RO process controllers to make frequent, significant operational adjustments (in order to maintain constant RO productivity), which may lead to chronic, excessive fluctuations of $\mathrm{RO}$ feed pressures that can potentially induce telescoping damage to RO membrane elements $[25,26]$.

Instead of using UF filtrate, RO concentrate or permeate can be utilized for UF backwash. Previous studies have indicated that demineralized water can enhance UF backwash effectiveness by reducing charge screening effects and thus natural organic matter (NOM) affinity to negatively-charge UF membrane surfaces [27, 28]. Pilot plant studies have also shown that backwash using RO permeate is more effective than with UF filtrate [29]. Utilization of RO 
permeate for backwash, however, does require the use of permeate storage and additional backwash pump, with the disadvantage of loss of RO productivity. The alternative technology of direct use of RO concentrate for UF backwash, as disclosed by UCLA [30], is particularly beneficial since it enables UF operation at $100 \%$ UF recovery (i.e. no loss of UF permeate). A later pilot study confirmed that UF backwash using RO concentrate (collected in a backwash tank and delivered via a backwash pump) can be as effective as using UF filtrate [31]. In this regard, it is interesting to note that periodic hyperosmotic stress has been suggested to slow the maturation process of marine bacterial biofilm growing on filtration membranes, induced by cell mortality [32]. Although previous work has suggested the potential benefits of UF backwash with RO concentrate, direct UF-RO integration has not yet been evaluated to demonstrate its advantage of flexible backwashing strategy without loss of UF or RO productivity.

In the present study, a directly integrated UF-RO system with UF backwash using RO concentrate was developed, eliminating the need for intermediate UF filtrate tank and backwash pump, enhancing operational flexibility, and enabling implementation of self-adaptive backwashing strategies. For the above system design, the hydrodynamics of the UF pre-treatment and RO desalination systems are coupled. Therefore, UF operational changes will directly impact the flow rate and inlet pressure to the high pressure RO feed pump, thereby necessitating an effective control strategy for regulating the above process variables. Typically, two to three times the filtration flux is recommended for effective UF backwash [6, 33]. However, the RO concentrate flow rate, while continuously available for backwash, is insufficient to meet the above criterion. Therefore, continuous UF backwash with RO concentrate was enhanced via a high flow rate RO concentrate pulse. The above approaches, which also facilitated the implementation of self-adaptive triggering, was evaluated in a seawater desalination field study deploying a novel UF-RO system consisting of multi-bore UF membranes and spiral-wound RO 
elements. The study was conducted to assess operational control strategy of the integrated UFRO plant, as well as the effectiveness of self-adaptive UF backwash (with RO concentrate) relative to both constant backwash frequency and freshwater backwash.

\section{Direct UF-RO Integration}

Direct UF-RO system integration, in contrast with conventional UF-RO systems (Fig. 1), involves feeding UF filtrate directly to the RO high pressure feed pump and RO concentrate directly for UF backwash (Fig. 2). The need for a UF backwash pump is eliminated since the RO concentrate is pressurized but throttled to a level that is suitable for UF backwash. It is noted that for an RO system with an energy recovery device (ERD), energy recovery would be set to a level that provides sufficient residual RO concentrate pressure for backwash. Direct UF-RO integration provides continuous RO concentrate flow (derived from UF operation at $100 \%$ recovery) and thus reduces the constraint on UF backwash period and frequency, thereby allowing for more flexible self-adaptive UF backwash strategies.

UF membranes require periodic backwash during which the membrane modules being backwashed are not producing UF filtrate. Moreover, since the systems are dynamically coupled, unsteady-state UF operation will impact RO operation. Changes to the UF filtrate flow rate, which is equal to the RO feed flow rate, would require the RO system to adjust its operating parameters (e.g. RO feed pressure, recovery). Typically, it is preferred to operate RO systems at a set freshwater productivity target [34] and avoid frequent (or unnecessary) RO feed pressure changes that can result in telescoping of RO elements $[25,26]$. Thus, for the operation of an integrated UF-RO system, it is desirable to minimize fluctuations of RO operation (e.g., during UF filtration/backwash transitions). 
It is generally accepted that effective UF backwash requires backwash flux that is approximately two to three times the UF filtrate flux for current UF elements [6, 33]. For a directly integrated UF-RO system (Fig. 2), the UF filtrate flux $\left(J_{U F}\right)$ is determined by the total UF filtrate flow rate $\left(Q_{U F}\right)$, the total number of UF membrane modules in filtration mode (i.e., not being backwashed), and the active UF membrane area per module $\left(A_{m}\right)$ :

$$
J_{U F}=\frac{Q_{U F}}{n \cdot A_{m}}
$$

The steady-state UF backwash flux depends on the available RO concentrate flow rate, which is governed by the RO feed flow rate (equivalent to $\left.Q_{U F}\right)$, the RO water recovery $\left(Y_{R O}\right)$, and the number of UF membrane modules in backwash $(k)$ :

$$
J_{B W, S S}=\frac{\left(1-Y_{R O}\right) \cdot Q_{U F}}{k \cdot A_{m}}
$$

The ratio of the steady-state UF backwash flux to the filtration flux can then be expressed as follows:

$$
\frac{J_{B W, S S}}{J_{U F}}=\left(1-Y_{R O}\right) \cdot \frac{n}{k}
$$

For certain applications (e.g. high recovery operations), UF backwash with the RO concentrate stream cannot be achieved at or above the recommended $J_{B W, S S} / J_{U F}$ ratio of 2-3 (e.g. for a system with $Y_{R O}=60 \%, n=3$, and $k=1, J_{B W, S S} / J_{U F}$ ratio is 1.2). Therefore, in order to maintain effective UF backwash during integrated UF-RO operation, it is critical to introduce a method of increasing the backwash flux (Section 2.1.2).

\subsection{UF Backwash}

\subsubsection{UF System Valve Configuration}

In order to maintain a constant RO feed flow rate during UF membrane backwash, the UF system requires membrane modules whose operation can be independently configured. In such a 
system (Fig. 3), feed filtration can take place through all the UF modules simultaneously or through only some of the modules. At all times at least one or more of the UF units are in operation, at the required flux, in order to provide the RO system with its required feed flow rate. When backwash is initiated for specific UF modules, their operational mode is transitioned from filtration to backwash while the filtration flux for the remaining modules is increased to accommodate the required $\mathrm{RO}$ feed. The above transitions can be done in any order and for any number of UF membrane modules as long as a reasonable number of UF membrane module remains in filtration mode to provide the needed RO feed.

\subsubsection{Pulse Backwash}

A pulse of a high RO concentrate backwash flux, for enhancing the effectiveness of UF backwash, can be achieved using a hydraulic accumulator on the RO concentrate backwash line (Fig. 4). During backwash operation, RO concentrate is partially diverted (by restricting backwash flow) to charge the accumulator. The accumulated RO concentrate is subsequently discharged into the backwash line to provide a short burst of high flow rate RO concentrate backwash. In the above approach, the total backwash flow rate, $Q_{B W}$, is the sum of the RO concentrate, $Q_{C}$, and accumulator discharge/charge, $Q_{A}$, flow rates:

$$
Q_{B W}=Q_{C}+Q_{A}
$$

For RO operation at constant productivity and recovery $Q c$ is time invariant while $Q_{A}$ is an accumulator discharge flow rate that rises to a maximum to achieve a significant (short-term) increase of the overall UF backwash flow rate. The discharge flow rate from hydraulic accumulator is governed by the pressure decreases in the accumulator bladder where the gas undergoes essentially adiabatic expansion during the discharge period [35-37]. Therefore, one should expect a discharge flow rate that increases to a maximum and then decreases as the 
pressure in the accumulator decreases. Rapid filling of the accumulator with the RO concentrate and subsequent discharge are achieved via a fast-acting flow restrictor valve downstream of the UF backwash line. When engaged, the flow restrictor valve increases the RO backwash line pressure, thereby forcing concentrate to flow into the accumulator (i.e. value of $Q_{A}$ is negative) and thus reducing $Q_{B W}$ (i.e., the continuous portion of the backwash flow stream). Immediately after the accumulator is filled (indicated when the pressure $P_{A}$ is at steady state; Fig. 4), the flow restrictor valve is disengaged, causing a rapid pressure decrease and correspondingly discharge of the accumulated RO concentrate. Throughout the backwash pulse (i.e., accumulator filling/discharge cycle) the RO feed pressure is maintained via a feedback controller on the RO pressure regulator valve as described previously [38].

\subsubsection{UF Self-Adaptive Backwash Triggering}

UF backwash that is triggered by a set level of UF transmembrane pressure (TMP) has been shown to be more effective than fixed backwash frequency [24]. However, implementation of such a strategy in conventional UF-RO with an intermediate UF filtrate storage tank (Fig. 1) has to consider: (a) the level of acceptable backwash effectiveness versus the reduction in UF productivity (i.e., due to utilization of UF filtrate), (b) balancing the flows of the UF feed, RO feed, and UF backwash streams, and (c) constraints on flux and its duration that are imposed by the finite water volume stored in the UF filtrate storage tank, thereby limiting the water volume available for UF backwash. In contrast, direct UF-RO integration with utilization of RO concentrate for UF backwash (without intermediate storage tanks) enables implementation of adaptive backwash with reduced constraints on backwash frequency and duration.

Reliance on variable backwashing strategy in which backwash is triggered when the UF membrane TMP exceeds a critical level is impractical for an integrated UF-RO. The reason for 
the above is readily apparent when considering the relationship between UF filtrate flux $\left(J_{U F}\right)$ and UF membrane TMP $\left(\Delta P_{m}\right)$ can be expressed using Darcy's law $[39,40]$ :

$$
J_{U F}=\frac{Q_{U F}}{n \cdot A_{m}}=\frac{\Delta P_{m}}{\mu \cdot R_{T}} \quad, \quad R_{T}=\frac{n \cdot A_{m} \cdot \Delta P_{m}}{\mu \cdot Q_{U F}}
$$

where $R_{T}$ is the total UF resistance (i.e., membrane and foulant layer) and $\mu$ is the water viscosity. As the membrane filtration flux changes (when membranes are taken off line for backwash, i.e., $n$ in Eq. 5 is reduced), the TMP must be increased to accommodate the needed RO feed flow. Therefore, the impact of fouling is not properly reflected by the TMP change. Therefore, for an integrated UF-RO system, the UF resistance, $R_{T}$, is a better metric for triggering backwash since it is an intrinsic function of the membrane and fouling resistances.

\subsection{Control of the UF System}

The UF system serves to pretreat the RO feed and thus the objective of its control system is to ensure that the UF filtrate flow rate required by the RO system is provided at the needed RO pump inlet pressure. A control scheme for regulating the above two control variables (UF filtrate flow rate and pressure) is illustrated in Fig. 5. The RO control system regulates its own feed flow rate subject to operational targets (e.g. productivity, recovery), thus dictating the flow rate through the entire system, while the UF control system regulates the pressure at the UF-RO interface. This architecture allows the UF and RO control systems to be decoupled (Fig. 5) despite the fact that the UF and RO system dynamics are coupled. For example, if the RO system mandates a RO feed flow rate adjustment (e.g. operator changes permeate productivity set-point), the flow rate through the entire system will change to match that value. The changes to UF filtrate flow rate will affect operating pressures such as the UF TMP (Eq. 5), the difference between UF feed and UF filtrate pressures. Since the UF control system's set-point is at the RO pump inlet pressure, the UF controller will change the UF feed pressure such that irrespective of 
the UF TMP, the UF outlet pressure (i.e., RO pump inlet pressure), remains at the established set-point and the UF feed flow rate continues to provide the required RO feed flow rate. Similarly, if any of the UF modules undergo backwash operation, the RO system will continue to draw the same flow rate through the UF system. However, during backwash (i.e. membrane modules are taken offline) less UF membrane area is available for filtration; therefore, a greater pressure drop is required to increase the UF filtrate flux and maintain constant UF filtrate flow rate. Here also, the UF control system will respond by increasing the UF feed pressure so that despite the increase in pressure drop across the UF system, the RO pump inlet pressure will remain the same. Simultaneously, such control action also ensures that the UF filtrate flow rate remains unaltered despite the reduction in available membrane area (i.e., the filtration flux increases for membranes remaining in filtration mode). In both examples, when either the UF or $\mathrm{RO}$ is undergoing an operational change, the UF and RO control systems do not need to exchange processed sensor data. This architecture allows for a greatly simplified and modular UF-RO integration that requires only physical connections of the two systems.

\section{Integrated UF-RO Pilot Plant Description and Field Study}

\subsection{Pilot Plant}

An integrated UF-RO plant was designed having permeate production capacity of 45.4 $\mathrm{m}^{3} /$ day (12,000 gallons/day) (Fig. 6). The UF pre-treatment system consisted of three hollowfiber (inside-out) UF modules (Dizzer 5000+, Inge, Greifenberg, Germany) each containing 50 $\mathrm{m}^{2}$ UF membrane elements. An array of actuators allowed for independent operation of each UF membrane module in either filtration or backwash mode (Section 2.1.1). A self-cleaning $200 \mu \mathrm{m}$ screen filter (TAF-500, Amiad, Mooresville, NC) was installed upstream of the UF unit. A centrifugal low-pressure UF pump (XT100 SS, 5 hp, Price Pump, Sonoma, USA) with VFD 
control (VLT AQUA Drive FC 202, 4.0 kW, Danfoss, Nordborg, Denmark) served for both UF feed and directing the UF filtrate to the RO feed pump.

The RO feed pump was a high-pressure axial piston positive displacement pump (APP 10.2, Danfoss, Nordborg, Denmark) with a premium efficiency motor (CEM4103T, $25 \mathrm{hp}$, TEFC, Baldor, Fort Smith, AR) and Variable Frequency Drive (VFD) control (VLT AQUA Drive FC 202, $22 \mathrm{~kW}$, Danfoss, Nordborg, Denmark). A minimum manufacturer recommended pump inlet pressure of $137.9 \mathrm{kPa}$ was specified in order to avoid cavitation. In addition, the RO feed pump is equipped with a sensor which cuts off power to the pump if the pump inlet pressure decreases below $50 \mathrm{kPa}$ in order to prevent pump damage. The RO pump efficiency was $91.5 \%$ as determined in the present study and had a manufacturer-specified operational range of outlet flow and pressure of 66-170 L/min and 2-8 MPa, respectively. The above specified minimum pump feed flow rate and pressure were required in order to ensure adequate pump selflubrication.

The UF filtrate was fed to the high pressure RO pump which then delivered the RO feed to three spiral-wound elements in series (Dow FILMTEC SW30HRLE-400, Dow, Edina, MN, USA). Each element was 8 inch diameter and 40 inch long housed in a fiberglass pressure vessel (8" End Ported, Protec Arisawa PRO-8-1000-EP-1, Vista, CA) with a manufacturer-specified maximum operating pressure of $6.89 \mathrm{MPa}(1000 \mathrm{psi})$. The manufacturer's reported RO element salt rejection was $99.65 \%$ (at $32,000 \mathrm{ppm} \mathrm{NaCl}, 800 \mathrm{psi}$ or $5.5 \mathrm{MPa}$ ) with a maximum water recovery per element of $15 \%$ enabling up to $38.6 \%$ total recovery with the three elements in series. An actuated needle valve (Mark 708LMO, Richard Industries, Cincinnati, OH), installed at the RO concentrate exit, along with the pump VFD, enabled control of both the feed pressure and flow rates. Two hydraulic bladder accumulators (C111ND, Blacoh Fluid Control, Riverside, CA, USA) were installed on the RO concentrate line to enable high flux pulse backwash. The 
system was equipped with a network of various sensors (conductivity, $\mathrm{pH}$, temperature, turbidity, and chlorophyll B), flow meters and pressure transducers interfaced with an embedded controller (cRIO-9022, National Instruments, Austin, TX USA) and data acquisition system.

\subsection{Control of RO Pump Inlet Pressure}

A transition from UF operational mode ( $n$ membrane modules configured for filtration) to backwash mode ( $n-k$ membrane modules configured for filtration, where $k$ is the number of UF modules undergoing backwash and where $n>k$ ) results in RO pump inlet pressure decrease (Section 2.2). This pressure decline could fall below the manufacturer recommended limit and can result in cavitation. In order to avoid such a pressure decline, a proportional-integral (PI) feedback controller was implemented for the UF pump VFD. The RO pump inlet pressure was set as the controlled variable for the feedback controller as per the PI control relation:

$$
V F D_{S P}^{U F}=K_{p}\left(P_{S P}-P(t)\right)+\frac{K_{p}}{\tau_{i}} \int_{0}^{t}\left(P_{S P}-P(\tau)\right) d \tau
$$

in which $V F D_{S P}^{U F}$ is the control action applied to the UF VFD in rpm, $P_{S P}$ is the pressure set-point for the RO pump inlet pressure, $K_{p}$ is the proportional gain, and $\tau_{i}$ is the integral time constant. Based on a series of system runs the optimal values of the PI control parameters were determined to be $K_{p}=0.798 \frac{\text { Valve } \%}{K P a}$ and $\frac{K_{p}}{\tau_{i}}=0.1 \mathrm{~s}$.

\subsection{UF Self-Adaptive Backwash}

Self-adaptive backwash triggering using overall UF membrane resistance (i.e. average resistance of 3 membrane modules), $R_{T}$, was implemented in the pilot UF-RO plant (Section 2.1.3). In self-adaptive mode, filtration for any given cycle is allowed to proceed until the incremental total resistance increase for a given cycle, $\Delta R_{T}$, reached a set threshold $\varepsilon$ (i.e. maximum allowable UF resistance increase). Backwash was triggered when 
where $R_{T}\left(t_{0, I}+\Delta t\right)$ is the UF membrane resistance at time $\Delta t$ after the beginning of a filtration cycle, and $R_{T}\left(t_{0, i}\right)$ (i.e. $\mathrm{R}_{\mathrm{T}, \mathrm{i}}$ for short) is the UF membrane resistance at the beginning of a filtration cycle. $R_{T}\left(t_{0, i}\right)$ at $i=1$ (i.e. first filtration cycle) is defined as $R_{m}$, the resistance of the clean membrane. UF backwash effectiveness can be ascertained by the degree of cumulative increase in overall resistance with progressive filtration/backwash cycles. Residual fouling, which cannot be removed by simple backwash (i.e. often termed irreversible fouling), typically occurs for desalination of most water sources (e.g., due to the strong adsorption of organic matter present in seawater including extracellular polymeric substances [41] and possibly pore-plugging [42]). When the overall resistance increases to the extent that the upper operating pressure limit for the UF membranes is reached, chemical cleaning in place (CIP) is typically required. Clearly, more effective backwash will lead to less residual fouling after each backwash and thus will retard the rate of increase of overall membrane fouling with progressive filtration/backwash cycles. In this regard, the goal of effective self-adaptive backwash strategy is to lower the rate of increase of $R_{T, i} / R_{m}$ and increase the operational period before CIP is required. More effective backwash will be indicated by a lower slope of $R_{T, i} / R_{m}$ versus time curve. In the current study, preliminary experiments were carried out, with UF backwash triggering at various resistance thresholds, revealing that $\varepsilon=1.36 \cdot 10^{11} \mathrm{~m}^{-1}$ was adequate for the present UF system as it enabled operation with at the lowest rate of normalized UF resistance $\left(R_{T, i} / R_{m}\right)$ increase.

In the present implementation of self-adaptive backwash, upon backwash triggering each of the three membrane modules are taken offline and backwashed in a sequential order. Accordingly, at any given time during the backwash period, two modules are always in filtration mode. Upon backwash triggering the first membrane module is put into backwash mode; once backwash is concluded the module is transitioned back to filtration operation. The above process 
is then applied sequentially to the second and then third module. Once all three modules have been backwashed, a new filtration period begins and all three membrane modules remain in filtration mode until the next backwash period is triggered; a complete filtration and backwash sequence is considered a filtration cycle.

\subsection{Field Study}

The directly integrated UF-RO pilot plant was deployed at the NAVFAC Seawater Desalination Test Facility in the Naval Base Ventura County (Port Hueneme, CA, USA). Raw seawater feed was pumped from an open-sea intake through strainer to the UF-RO pilot plant. The feed salinity $(33,440-36,800 \mathrm{mg} / \mathrm{L}$ total dissolved solids) and $\mathrm{pH}(7.5-8.2)$ varied within a relatively narrow range; however, variations of the feed total suspended solids (0.1-5.2 ppm), turbidity (0.4-14 NTU), and temperature $\left(11.2-19.7^{\circ} \mathrm{C}\right)$ were significant. The feed pretreatment system $(200 \mu \mathrm{m}$ screen filter and UF) provided water of turbidity $\lesssim 0.1$ NTU which was well below the recommended maximum limit for RO desalting [43]. Field tests included demonstration of the UF-RO control system, particularly the decoupled nature of the UF and RO control systems and its ability to maintain adequate RO pump inlet pressure during various UF transitions. Subsequently, the effectiveness of UF pulse backwash using RO concentrate delivered from the RO system to the UF unit was evaluated. Self-adaptive backwash that includes the above strategy was also implemented and its effectiveness was compared with the use of self-adaptive freshwater (i.e., RO permeate) backwash.

\section{Results \& Discussion}

\subsection{Performance of the Integrated UF-RO System Control Strategy}

The performance of the integrated UF-RO system control strategy, based on the control system architecture described in Fig. 5 and Section 2.2, was assessed from the observed dynamic 
system responses to various UF and RO controllers' set-point changes. First, the pilot plant was operated without control action to demonstrate why dynamic pressure control of the UF-RO interface is essential for the operation of an integrated UF-RO system. Operational parameters were set at an $\mathrm{RO}$ feed flow rate of $75.7 \mathrm{~L} / \mathrm{min}$ and $\mathrm{RO}$ pump inlet pressure of $137.9 \mathrm{kPa}$. The UF feed pump VFD was operated at a constant RPM without control action. When the UF system was transitioned from filtration to backwash, the number of UF membrane modules in filtration decreases from 3 to 2 and an increase in UF TMP was expected due to the decrease of membrane area available for filtration. Without control action, the UF feed pressure remained constant; thus when UF TMP was increased, the UF outlet pressure, or the RO pump inlet pressure, decreased (Fig. 7a). For this specific experiment, when the transition from filtration to backwash occurs, the pressure decreased rapidly within 2 seconds from $137.9 \mathrm{kPa}$ to $43.43 \mathrm{kPa}$, which caused a pump shut down (i.e. shut down threshold of below $50 \mathrm{kPa}$ ) (Section 3.1) as evidenced by the RO pump RPM going to zero (Fig. 7b).

The above illustration of the integrated UF-RO operation indicate that control of the UF-RO interface pressure (i.e. RO pump inlet pressure) is critical and accordingly the proposed control scheme as described in Sections 2.2 and 3.2 was implemented and tested. Illustration of the control system performance is shown in Fig. 8, where the RO feed flow rate set-point was changed from $90.7 \mathrm{~L} / \mathrm{min}$ to $77.29 \mathrm{~L} / \mathrm{min}$ (change induced by the RO controller) for a set RO operation at 35\% recovery and RO pump inlet pressure, or UF filtrate pressure set-point of 137.9 $\mathrm{kPa}$. The RO recovery was maintained through control of RO feed flow rate and RO feed pressure as described in an earlier study [38]. As expected, the RO inlet pressure increased somewhat (by up to $\sim 5 \mathrm{kPa}$, for $\sim 20 \mathrm{sec}$ ) due to the decreased system flow rate leading to a decrease in UF TMP. However, the UF feedback controller effectively adjusted (via reduction of the UF feed pump motor speed) the pressure to the set-point RO pump inlet pressure constant. 
In a subsequent experiment, the ability of the UF controller to handle filtration/backwash UF transitions that affect the RO pump inlet pressure was demonstrated. In this test self-adaptive backwash triggering was implemented based on the UF membrane resistance as described in Section 3.3. The operation of the RO unit was at a set feed flow rate of $75.7 \mathrm{~L} / \mathrm{min}$ and permeate recovery of $35 \%$. The RO pump inlet pressure set-point of $137.9 \mathrm{kPa}$ was maintained by the UF controller. During filtration mode, the flow rate through each membrane module was $25.2 \mathrm{~L} / \mathrm{min}$ (flux of $10.1 \mathrm{~L} / \mathrm{m}^{2} \mathrm{~h}$ ), while during backwash (with two membranes modules in filtration mode), the flow rate through each module was $37.9 \mathrm{~L} / \min \left(\right.$ flux $15.1 \mathrm{~L} / \mathrm{m}^{2} \mathrm{~h}$ ). A sharp rise in the TMP is apparent upon transition from filtration to backwash (Fig 9b). In contrast, the progressive increase in UF membrane resistance is a clear indication of progressive fouling. Moreover, this metric is not altered by the flux change imposed when other membranes are being placed in backwash mode. In addition, as shown in Fig. 9c, the RO pump inlet pressure is effectively maintained at its set-point despite the repeated filtration/backwash transitions.

\subsection{UF Pulse Backwash using RO Concentrate}

An evaluation of the suitability of pulse backwash for enhancing the UF backwash flux was undertaken with the seawater desalination system operating at $30 \%$ recovery for RO feed flow rate of $167.5 \mathrm{~L} / \mathrm{min}$, For the above operation, UF filtrate flux during filtration with all three modules was $67.0 \mathrm{~L} / \mathrm{m}^{2} \mathrm{~h}$. The maximum attainable backwash flux, via direct use of RO concentrate flow from the RO system was $140.6 \mathrm{~L} / \mathrm{m}^{2} \mathrm{~h}(\mathbf{E q}$. 2), which was significantly below the manufacturer recommended UF backwash flux of $230 \mathrm{~L} / \mathrm{m}^{2} \mathrm{~h}$ [33]. Backwash flux enhancement can be achieved with a hydraulic accumulator as illustrated in Fig. 10. As the accumulator is charged (typically over a period of $\sim 40 \mathrm{~s}$ ) the continuous concentrate backwash flux (Section 2.1.2; Fig. 10) decreases initially, but then was restored as the accumulator was 
fully charged. Upon discharging accumulator, the attained pulse backwash flux was above the manufacturer recommended value, increasing up to a maximum value $\left(287.6 \mathrm{~L} / \mathrm{m}^{2} \mathrm{~h}\right)$ being a factor of 4.3 above the filtration flux.

Although the high backwash flux was achieved for a short period it was effective for achieving effective UF backwash that restored membrane permeability and prevented progressive irreversible fouling. A demonstration of the benefit of using the pulsed backwash is shown in Fig. 11 for operation over a period of about 8 days. Two separate tests (with and without pulse UF backwash) were conducted with the RO unit operating at the same condition as in the previous experiment. For UF backwash operation without a pulse the backwash period was set to 3 minutes. UF backwash with a pulse was carried out with 2 pulses (each lasting $40 \mathrm{~s}$ ) followed 2 minutes of direct RO concentrate backwash. In both cases the UF unit was operated in a self-adaptive mode for backwash triggering (Section 3.3). Comparison of the normalized UF resistance $\left(R_{T, i} / R_{m}\right)$ with and without pulse backwash (Fig. 11) clearly indicates progressive fouling for the latter operation due to ineffective backwash. In contrast, after an initial stabilization period (within $\sim 48 \mathrm{~h}$ ), the normalized UF membrane resistance did not appreciably change remaining at a value of $1.15 \pm 0.05$. It is noted that by the end of the test period the normalized UF membrane resistance for operation without pulse backwash was about $26 \%$ higher than operation employing with pulse backwash. The above test demonstrates that, even with self-adaptive operation, pulse backwash is essential for effective UF backwash.

\subsection{Effectiveness of Self-Adaptive Backwash Strategy}

The effectiveness of self-adaptive UF backwash (Section 3.3) with pulse backwash was evaluated in three comparative field test: (i) RO concentrate UF backwash at a fixed frequency of backwash triggering every 18 min (constant backwash), (ii) RO concentrate UF backwash 

permeate) UF backwash for a duration of 30 s at a flux equal to the maximum attainable pulse backwash flux (287.6 L/m² $\mathrm{h})$, also with self-adaptive backwash triggering (freshwater backwash). In tests (i) and (ii) UF backwash consisted of two pulses ( $40 \mathrm{~s}$ each) followed by 2 minutes of direct RO concentrate backwash. For experiment (i), a backwash triggering frequency of 18 minutes was selected to match the average backwash frequency for experiment (ii) with selfadaptive backwash. It is noted that test (i) was terminated earlier than the other two test in order to protect the UF membranes given the significantly higher fouling rate in test (i). In test (iii), a backwash duration of 30s was chosen based on preliminary runs since this was the shortest duration that resulted in the lowest rate of UF resistance increase. For the above tests the UF feed flow rate was $75.7 \mathrm{~L} / \mathrm{min}$ and the $\mathrm{RO}$ operation was at $35 \%$ recovery. Results for the above three tests (Fig. 12) showed that UF membrane resistance increased, essentially linearly, with time. It is noted that the UF membrane modules have a maximum (manufacturer-specified) operating $\Delta \mathrm{P}_{\mathrm{m}}$ limit of $20 \mathrm{psi}$ [33], which, when only two modules are filtering (flux of $45.42 \mathrm{~L} / \mathrm{m}^{2} \mathrm{~h}$ ) the maximum allowable normalized UF resistance is 3.1. For UF operation with self-adaptive RO concentrate pulse backwash, the UF system would be expected to operate for approximately 3,433 hours ( $\sim 43$ days, or $\sim 4.8$ months) before reaching the above operational limit. Operation at a fixed UF backwash frequency with RO concentrate was estimated to enable operation of up to 381 hours before reaching the above operational limit. For self-adaptive UF operation with freshwater backwash, UF operation up to 4,919 hours ( 205 days, or $\sim 6.8$ months) would have been possible. Considering that chemical cleaning would be necessary once the operational pressure limit (or maximum allowable resistance) have been reached, the projected operating duration (before chemical cleaning was required) is $901 \%$ longer with self-adaptive RO concentrate pulse backwash than with constant (fixed frequency) backwash. The projected 
operating duration was $143 \%$ higher with self-adaptive freshwater backwash over the selfadaptive RO concentrate backwash. However, it is important to recognize that freshwater backwash effectively lowered the overall water recovery of the UF-RO system to $24.5 \%$ (i.e. compared to $35 \%$ when using RO concentrate for backwash) and thus increased the overall energy consumption per volume of produced permeate by about $40 \%$.

\section{Conclusions}

A novel RO desalination system was developed that directly integrates UF pretreatment of RO feed whereby UF backwash is accomplished using the RO concentrate. This direct integration reduces the overall system footprint through elimination of intermediate storage tanks and UF backwash pump which also reduces associated maintenance costs, while allowing for flexible and effective UF backwash strategies. Given the unique decoupling of the RO and UF systems control, RO productivity can be set independently of the UF system which is able to autonomously adjust and provide the RO system with the required RO feed and at the set inlet RO pump pressure. Self-adaptive backwash in the present system was implemented by integrating direct diversion of $\mathrm{RO}$ concentrate from the $\mathrm{RO}$ system for continuous and sequential backwash with pulse backwash using a hydraulic accumulator. It is noted that while self-adaptive backwash with RO permeate was somewhat more effective than with RO concentrate, this approach resulted in reduced permeate production $(\sim 35 \%)$ and higher (by $\sim 40 \%)$ overall energy cost per volume of permeate product. Seawater desalination field studies demonstrated that triggering of UF backwash with RO concentrate, based on a membrane resistance threshold, was superior to fixed frequency backwash extending the projected UF operation from about 16 to 143 days before requiring CIP. The above results suggest that there is merit in exploring further 
enhancement of UF filtration and backwash effectiveness by integrating coagulation with the present self-adaptive UF backwash.

\section{Acknowledgements}

This work was funded, in part, by the United States Office of Naval Research, the California Department of Water Resources, U.S. Bureau of Reclamation, and the UCLA Water Technology Research (WaTeR) Center. The authors would like to acknowledge the contributions of Dr. Richard Zhu, Dr. Alex Bartman, and John Thompson in the construction of the pilot. The authors also acknowledge contributions of equipment and materials by Danfoss Sea Recovery (Henrik Wendelboe and Christopher Okada), Inge GmbH (Peter Berg, Martin Heijnen, and Josef Wunram), George Fisher (Rick Hines), and Dow Water \& Process Solutions (Michael Kim), Ahlstrom (Rod Komlenic and Denise Russell) for equipment contributions toward construction of the desalination plant. The personnel of the Seawater Desalination Test Facility at the US Naval Base Ventura County (William Varnava, Mark Miller, Paul Giuffrida, and Micah Ing) are also acknowledged for their assistance during the field study. The presented material is based, in part, upon research performed in a UCLA WaTeR Center laboratory renovated through National Science Foundation Grant No. 0963183, which is an award funded under the American Recovery and Reinvestment Act of 2009 (ARRA).

\section{References}

[1] S. Gray, R. Semiat, M. Duke, A. Rahardianto, Y. Cohen, 4.04 - Seawater Use and Desalination Technology, in: W. Editor-in-Chief: Peter (Ed.) Treatise on Water Science, Elsevier, Oxford, 2011, pp. 73-109.

[2] Y. Cohen, B. McCool, A. Rahardianto, M.-m. Kim, J. Faria, Membrane desalination of agricultural drainage water, in: Salinity and Drainage in San Joaquin Valley, California, Springer Netherlands, 2014, pp. 303-341.

[3] H.C. Flemming, G. Schaule, T. Griebe, J. Schmitt, A. Tamachkiarowa, Biofouling-the Achilles heel of membrane processes, Desalination, 113 (1997) 215-225.

[4] L. Henthorne, B. Boysen, State-of-the-art of reverse osmosis desalination pretreatment, Desalination, 356 (2015) 129-139. 
[5] L.O. Villacorte, S.A.A. Tabatabai, D.M. Anderson, G.L. Amy, J.C. Schippers, M.D. Kennedy, Seawater reverse osmosis desalination and (harmful) algal blooms, Desalination, 360 (2015) 6180 .

[6] K.T. Chua, M.N.A. Hawlader, A. Malek, Pretreatment of seawater: Results of pilot trials in Singapore, Desalination, 159 (2003) 225-243.

[7] M. Wilf, M.K. Schierach, Improved performance and cost reduction of RO seawater systems using UF pretreatment, Desalination, 135 (2001) 61-68.

[8] P.H. Wolf, S. Siverns, S. Monti, UF membranes for RO desalination pretreatment, Desalination, 182 (2005) 293-300.

[9] K. Burashid, A.R. Hussain, Seawater RO plant operation and maintenance experience: addur desalination plant operation assessment, Desalination, 165 (2004) 11-22.

[10] A. Brehant, V. Bonnelye, M. Perez, Comparison of MF/UF pretreatment with conventional filtration prior to RO membranes for surface seawater desalination, Desalination, 144 (2002) 353-360.

[11] A. Teuler, K. Glucina, J.M. Laîné, Assessment of UF pretreatment prior RO membranes for seawater desalination, Desalination, 125 (1999) 89-96.

[12] O. Lorain, B. Hersant, F. Persin, A. Grasmick, N. Brunard, J.M. Espenan, Ultrafiltration membrane pre-treatment benefits for reverse osmosis process in seawater desalting. Quantification in terms of capital investment cost and operating cost reduction, Desalination, 203 (2007) 277-285.

[13] D.F. Halpern, J. McArdle, B. Antrim, UF pretreatment for SWRO: pilot studies, Desalination, 182 (2005) 323-332.

[14] M. Kazemimoghadam, T. Mohammadi, Chemical cleaning of ultrafiltration membranes in the milk industry, Desalination, 204 (2007) 213-218.

[15] P. Blanpain-Avet, J.F. Migdal, T. Bénézech, Chemical cleaning of a tubular ceramic microfiltration membrane fouled with a whey protein concentrate suspension-Characterization of hydraulic and chemical cleanliness, J Membrane Sci, 337 (2009) 153-174.

[16] L. Quinn, Reverse osmosis systems in military or emergency operations, Desalination, 113 (1997) 297-301.

[17] J. Chen, G. Li, Marine reverse osmosis desalination plant - a case study, Desalination, 174 (2005) 299-303.

[18] R. Ordóñez, D. Hermosilla, I.S. Pío, Á. Blanco, Evaluation of MF and UF as pretreatments prior to RO applied to reclaim municipal wastewater for freshwater substitution in a paper mill: A practical experience, Chemical Engineering Journal, 166 (2011) 88-98.

[19] A.P. Echavarría, V. Falguera, C. Torras, C. Berdún, J. Pagán, A. Ibarz, Ultrafiltration and reverse osmosis for clarification and concentration of fruit juices at pilot plant scale, LWT - Food Science and Technology, 46 (2012) 189-195.

[20] C.W. Aeijelts Averink, W. Buijs, Recycling of water with canal water supplement at Artis Zoo, Amsterdam, by means of ultrafiltration and reverse osmosis, Desalination, 132 (2000) 167171.

[21] M. Aboabboud, S. Elmasallati, Potable water production from seawater by the reverse osmosis technique in Libya, Desalination, 203 (2007) 119-133.

[22] D.A. Seiberling, Appendix B - Tank Cleaning, in: S. Hall (Ed.) Branan's Rules of Thumb for Chemical Engineers (Fifth Edition), Butterworth-Heinemann, Oxford, 2012, pp. 429-432. [23] R. Rautenbach, T. Linn, D.M.K. Al-Gobaisi, Present and future pretreatment concepts strategies for reliable and low-maintenance reverse osmosis seawater desalination, Desalination, 110 (1997) 97-106. 

backwash initiation in membrane systems, J Membrane Sci, 278 (2006) 381-389.

[25] Dow, FilmTec's Technical Manual.

[26] A. Basile, A. Cassano, N.K. Rastogi, Advances in Membrane Technologies for Water Treatment: Materials, Processes and Applications, Elsevier Science, 2015.

[27] A.J. Abrahamse, C. Lipreau, S. Li, S.G.J. Heijman, Removal of divalent cations reduces fouling of ultrafiltration membranes, J Membrane Sci, 323 (2008) 153-158.

[28] S. Li, S.G.J. Heijman, J.Q.J.C. Verberk, A.R.D. Verliefde, A.J.B. Kemperman, J.C. van Dijk, G. Amy, Impact of backwash water composition on ultrafiltration fouling control, J Membrane Sci, 344 (2009) 17-25.

[29] C. Ma, L. Wang, S. Li, S.G.J. Heijman, L.C. Rietveld, X.B. Su, Practical experience of backwashing with RO permeate for UF fouling control treating surface water at low temperatures, Separation and Purification Technology, 119 (2013) 136-142.

[30] Y. Cohen, P.D. Christofides, A. Rahardianto, A.R. Bartman, A. Zhu, H. Gu, L.X. Gao, Apparatus, system and method for integrated filtration and reverse osmosis desalination, in: US Patent Application Publication No. US20140048462 A1, US Patent App. 13/822,622, 2011.

[31] G. Gilabert-Oriol, M. Hassan, J. Dewisme, V. Garcia-Molina, M. Busch, Backwashing pressurized ultrafiltration using reverse osmosis brine in seawater desalination and its potential costs savings, Desalination and Water Treatment, (2014) 1-13.

[32] L. Katebian, S.C. Jiang, Marine bacterial biofilm formation and its responses to periodic hyperosmotic stress on a flat sheet membrane for seawater desalination pretreatment, Journal of Membrane Science, 425-426 (2013) 182-189.

[33] I. GmbH, Dizzer XL Ultrafiltration Modules, in, 2012.

[34] I. Alatiqi, H. Ettouney, H. El-Dessouky, Process control in water desalination industry: an overview, Desalination, 126 (1999) 15-32.

[35] É. Clapeyron, Mémoire sur la puissance motrice de la chaleur, Jacques Gabay, 1834.

[36] P. Chapple, Principles of Hydraulic Systems Design, Second Edition, Momentum Press, 2014.

[37] S. Mamèic, M. Bogdevièius, Simulation of dynamic processes in hydraulic accumulators, Transport, 25 (2010) 215-221.

[38] L. Gao, A. Rahardianto, H. Gu, P.D. Christofides, Y. Cohen, Energy-Optimal Control of RO Desalination, Industrial \& Engineering Chemistry Research, (2013).

[39] S. Whitaker, Flow in porous media I: A theoretical derivation of Darcy's law, Transp Porous Med, 1 (1986) 3-25.

[40] J. Kim, F.A. DiGiano, Fouling models for low-pressure membrane systems, Separation and Purification Technology, 68 (2009) 293-304.

[41] G. Crozes, C. Anselme, J. Mallevialle, Effect of adsorption of organic matter on fouling of ultrafiltration membranes, J Membrane Sci, 84 (1993) 61-77.

[42] Y.S. Polyakov, A.L. Zydney, Ultrafiltration membrane performance: Effects of pore blockage/constriction, J Membrane Sci, 434 (2013) 106-120.

[43] A.C. Chang, D.B. Silva, Salinity and Drainage in San Joaquin Valley, California: Science, Technology, and Policy, Springer London, Limited, 2013. 


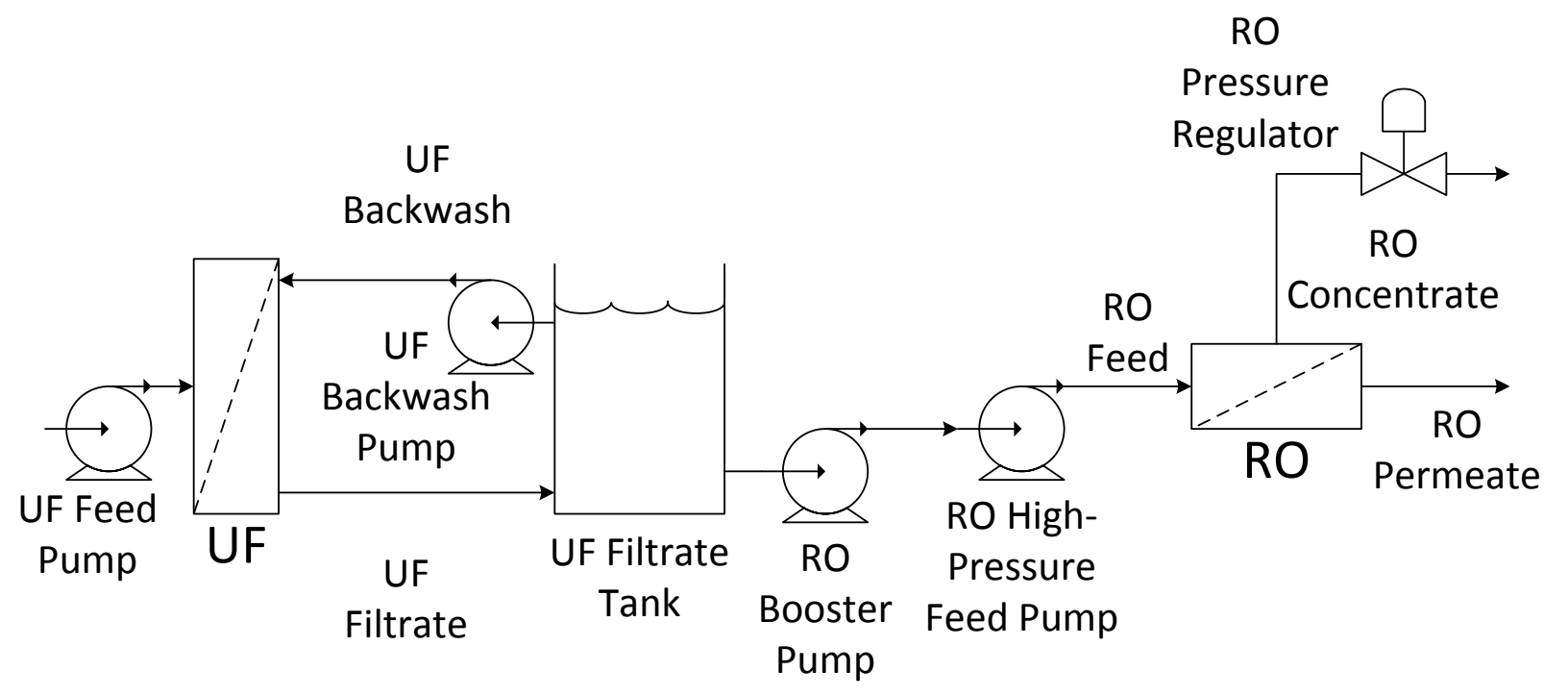

Figure 1. Process diagram of a conventional integrated UF-RO system design that utilizes an intermediate UF filtrate storage tank for UF backwash water, UF backwash pump, and RO booster pump.

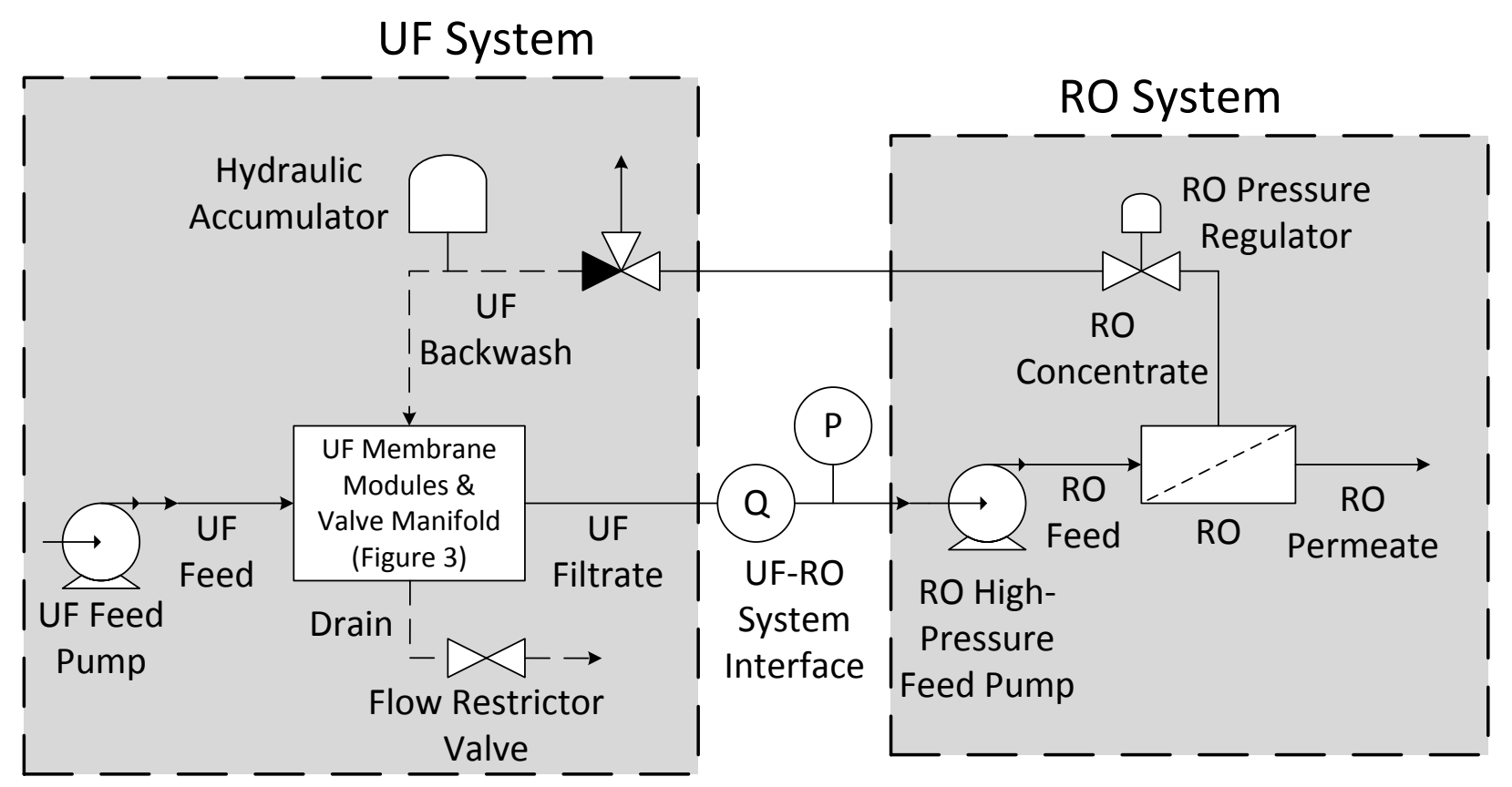

Figure 2. Process Diagram of a directly integrated UF-RO system. Flow rate $(Q)$ and pressure $(P)$ at the UF-RO system interface are maintained by the control system (Fig. 5). 


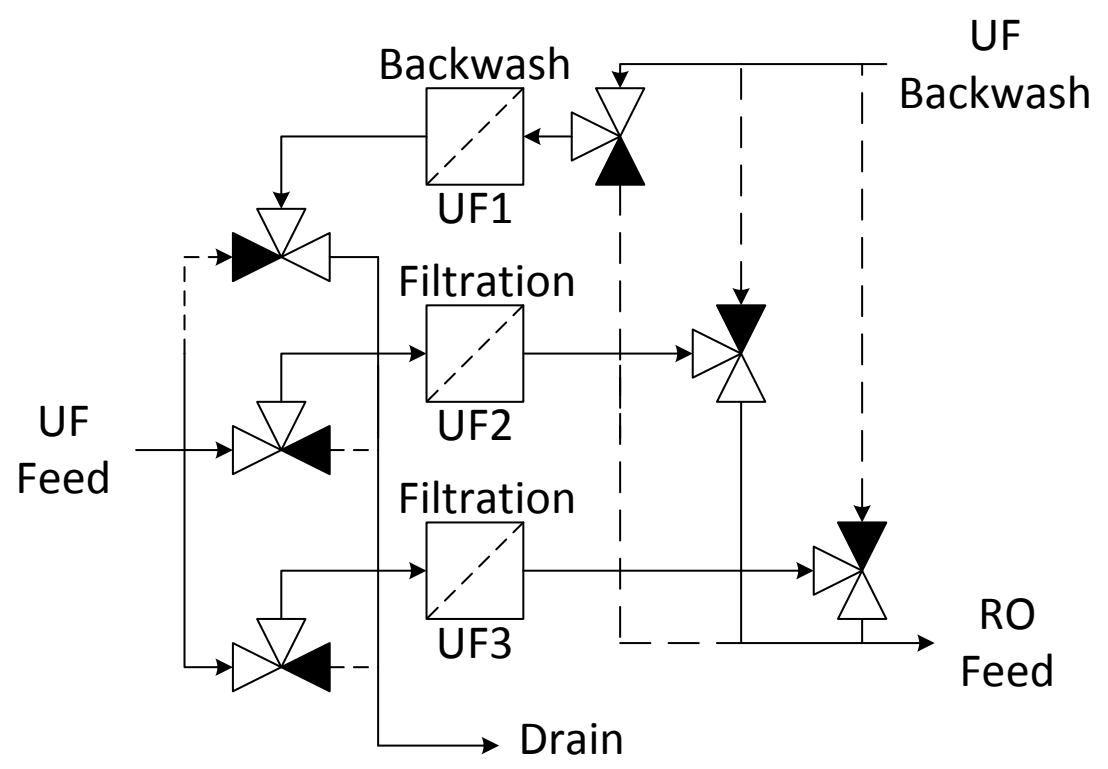

Figure 3. Process diagram of three independently configurable UF membrane modules. Note: Any single module (UF1, UF2, or UF3) can be backwashed while the others remain in filtration mode.

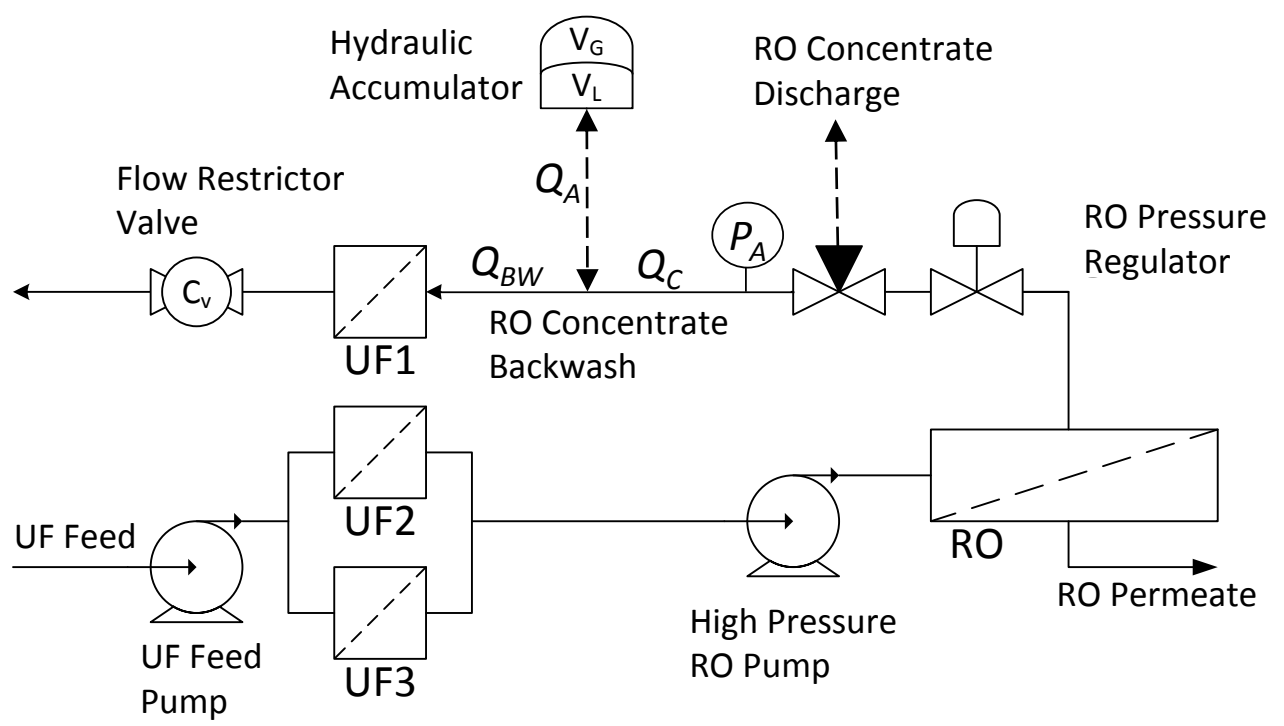

Figure 4. Process schematic for RO concentrate UF pulse backwash operation. A pulse of high concentrate flow rate (for UF backwash) is generated by a two-step sequential approach: a) engagement of flow restrictor valve to enable charging (i.e., filling) of the accumulator with $R O$ concentrate, $b$ ) open flow restrictor valve to discharge $R O$ concentrate from the accumulator. $P_{A}$ : $R O$ concentrate pressure (throttled); $Q_{C}: R O$ concentrate flow rate; $Q_{B W}: U F$ backwash flow rate; $Q_{A}$ : flow out of the accumulator; $V_{G}, V_{L}$ : gas and liquid volumes in the accumulator, respectively. 


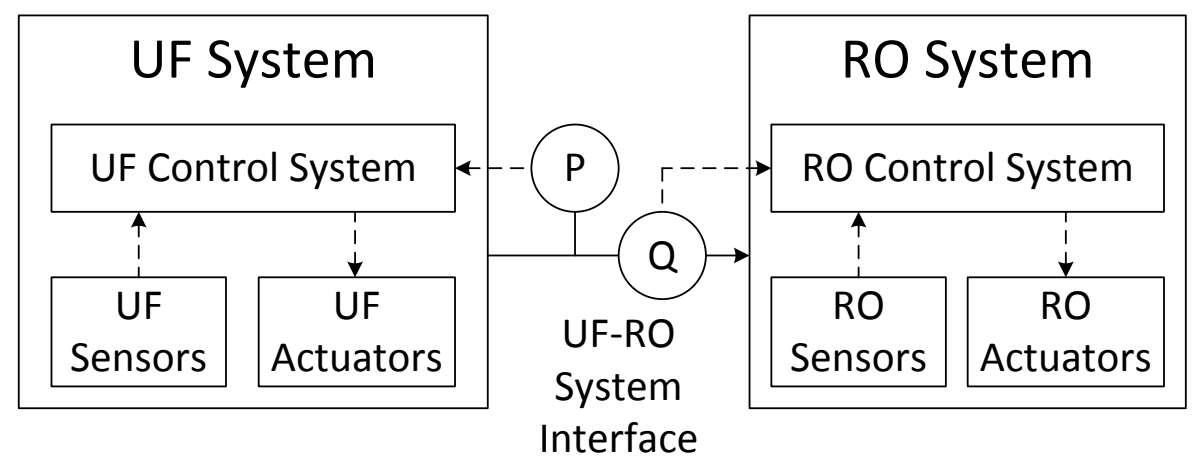

Figure 5. Illustration of a modular control architecture for an integrated UF-RO system, where the monitored flow rate $(Q)$ and pressure $(P)$ at the UF-RO interface are inputs to the decoupled $U F$ and RO controllers, respectively.

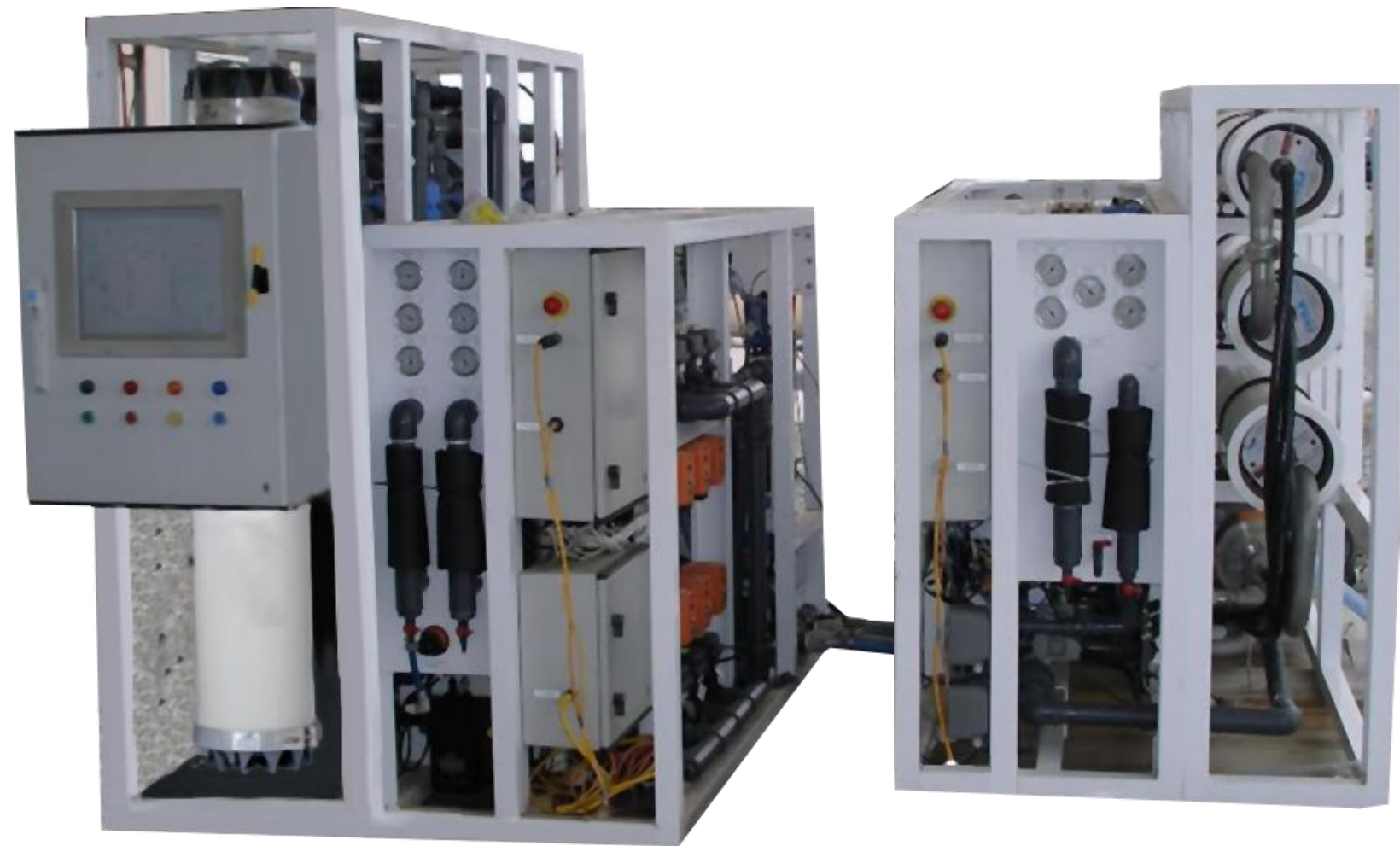

Figure 6. A pilot-scale desalination plant consisting of a UF and RO units that are directly integrated (Fig. 2). 


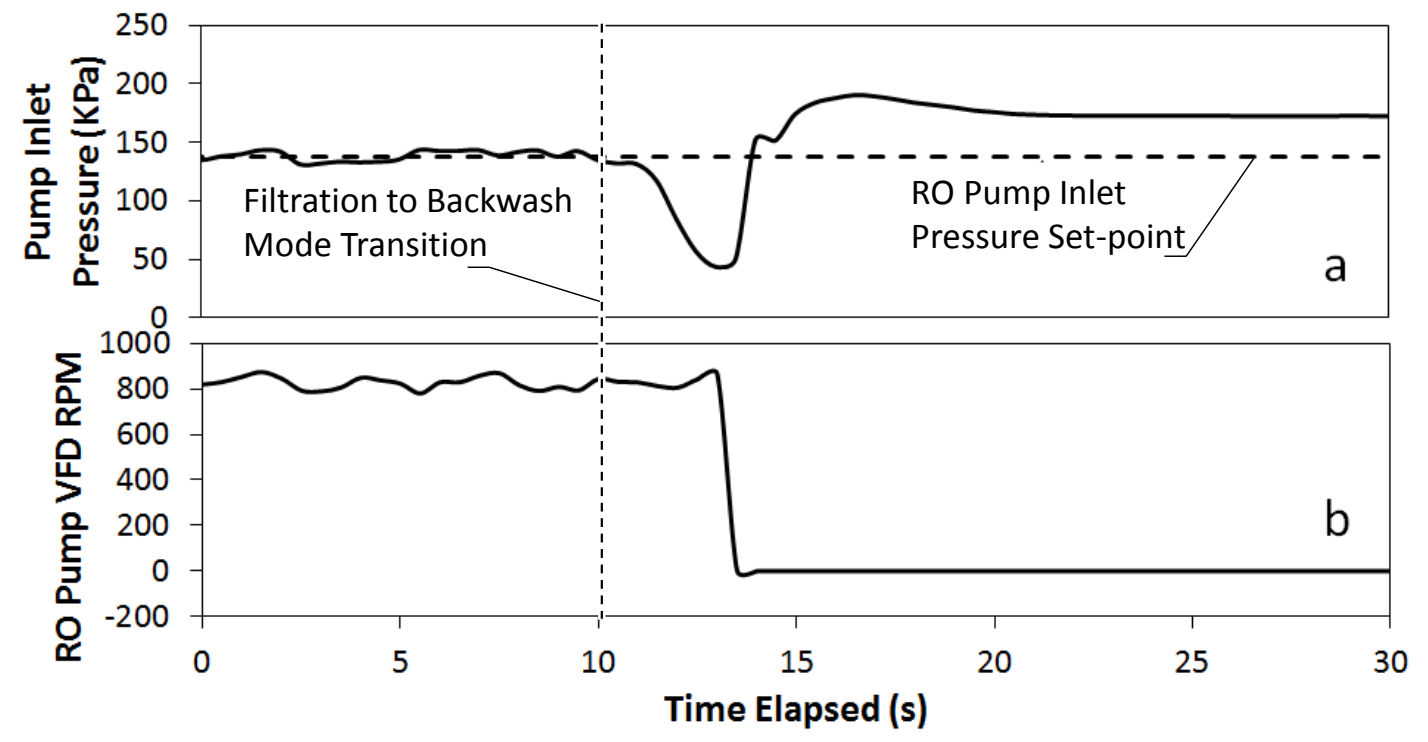

Figure 7: Illustration of time profiles of (a) RO pump inlet pressure and (b) RO pump VFD RPM during a transition from filtration (three modules filtering) to backwash mode (two modules filtering) without any control action. (UF inlet flow rate $=4.54 \mathrm{~m}^{3} / \mathrm{h}$ ).

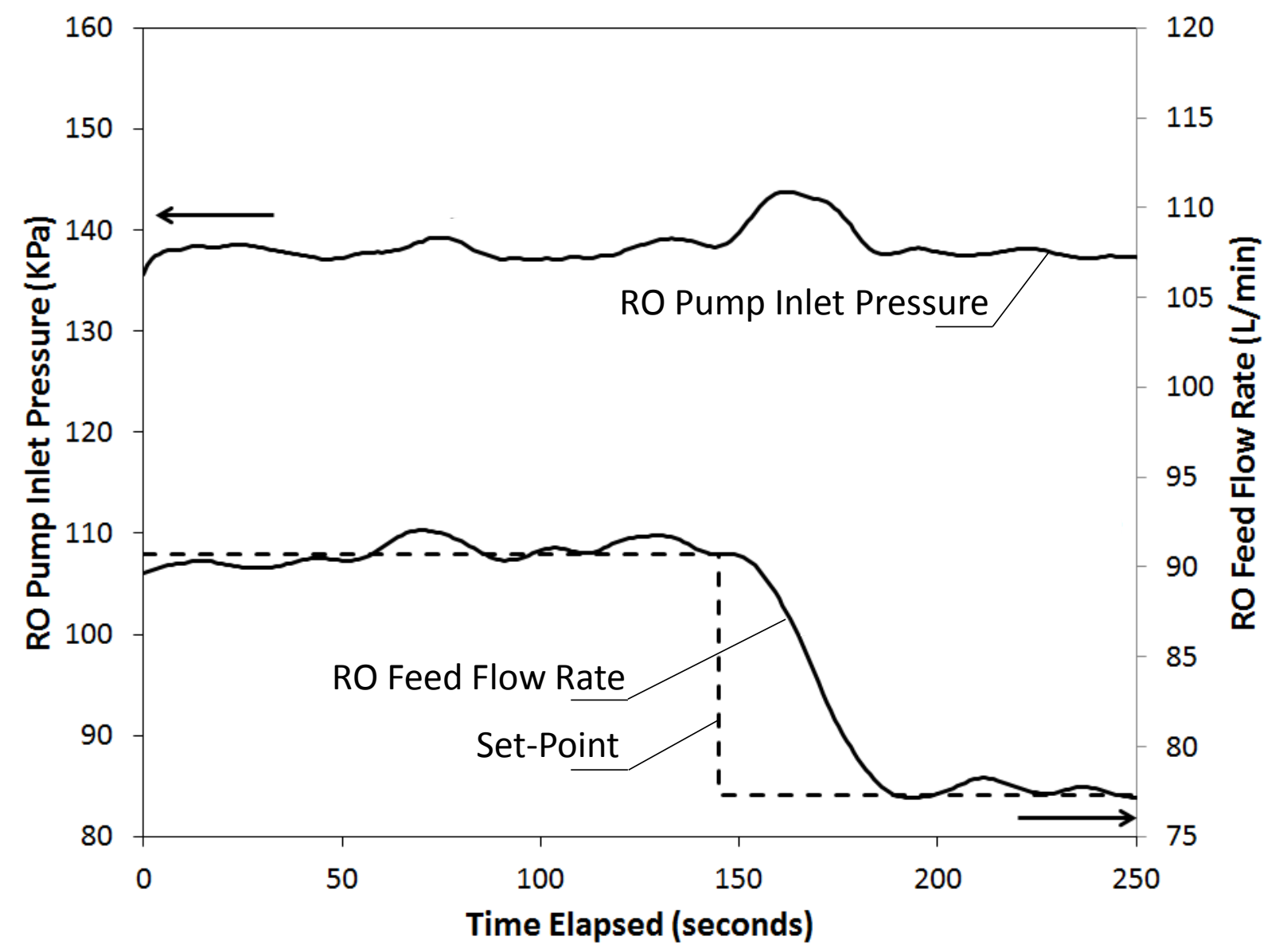

Figure 8. Effect of RO feed flow rate set point change on the time profiles of the RO pump inlet pressure and $R O$ feed flow rate. 


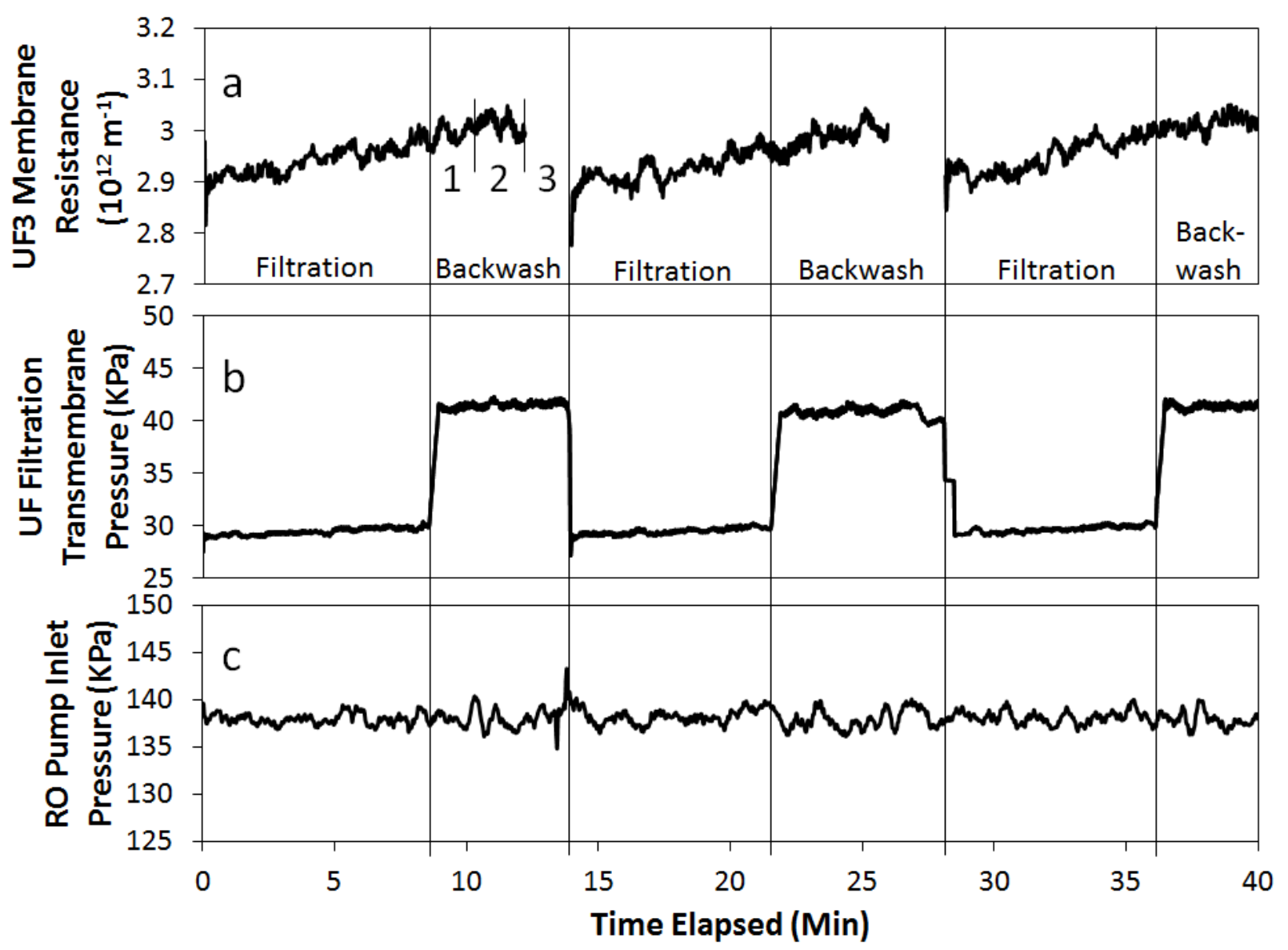

Figure 9. (a) UF3 module resistance, (b) UF transmembrane pressure, and (c) RO pump inlet pressure (at a set point of $137.9 \mathrm{kPa}$ ) during three consecutive filtration-backwash cycles. During each UF backwash period, only two membrane modules are filtering at any given time as the modules are backwashed sequentially one at a time (indicated by the numbers 1, 2, and 3 in a), resulting in temporary elevation of overall UF filtrate flux and thus UF trans-membrane pressure (in b). Disturbances resulting from UF backwash operations are overcome by the control actions of the UF controller maintaining a stable RO pump inlet pressure. (RO operation at $35 \%$ recovery for feed flow rate of $4.54 \mathrm{~m}^{3} / \mathrm{h}$; UF filtration flux: $10.1 \mathrm{~L} / \mathrm{m}^{2} \mathrm{~h}$ and $15.1 \mathrm{~L} / \mathrm{m}^{2} \mathrm{~h}$ during filtration (3 modules) and backwash (2 modules) modes, respectively). 


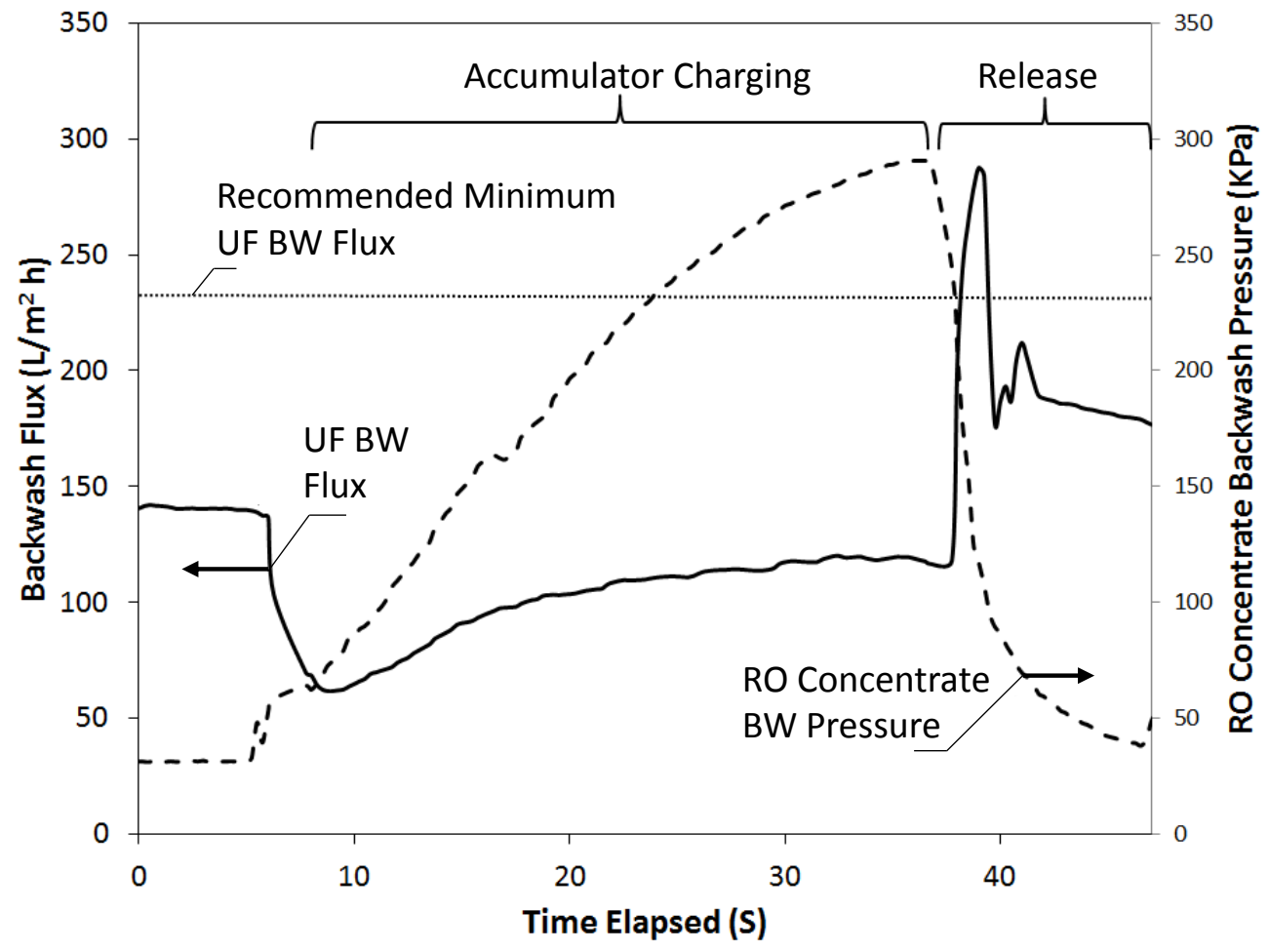

Figure 10. UF backwash (BW) flux for a single UF module and pressure during a pulse backwash operation using RO concentrate. Accumulator charging via flow restriction (Fig. 4) and discharge actuated by opening of the restrictor valve enables generation of a rapid pulse of high flow rate ( $239.7 \mathrm{~L} /$ min equivalent to backwash flux of $\left.287.6 \mathrm{~L} / \mathrm{m}^{2} \mathrm{~h}\right)$ of $R O$ concentrate for UF backwash, resulting in total backwash flux a factor of 4.3 times above the recommended minimum. It is noted that the backwash flux and pressure during the first 5 s are for direct backwash with the $R O$ concentrate, at a $R O$ concentrate flow rate of $117.3 \mathrm{~L} / \mathrm{min}$ or backwash flux of $140.6 \mathrm{~L} / \mathrm{m}^{2} \mathrm{~h}$.

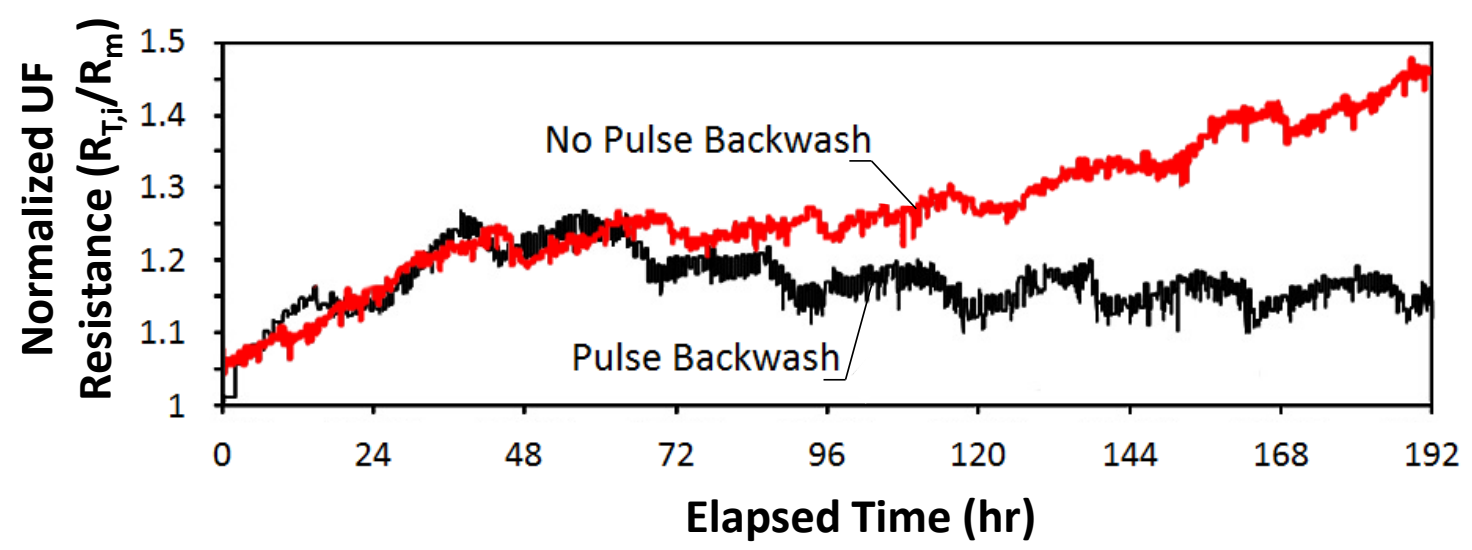

Figure 11. Comparison of the effect of RO concentrate backwash with and without pulse generation on the evolution of UF resistance (normalized with respect to the initial value). Operation of integrated UF-RO plant for seawater desalination (UF feed flow rate: $4.54 \mathrm{~m}^{3} / \mathrm{h}$; RO recovery: $35 \%)$. 


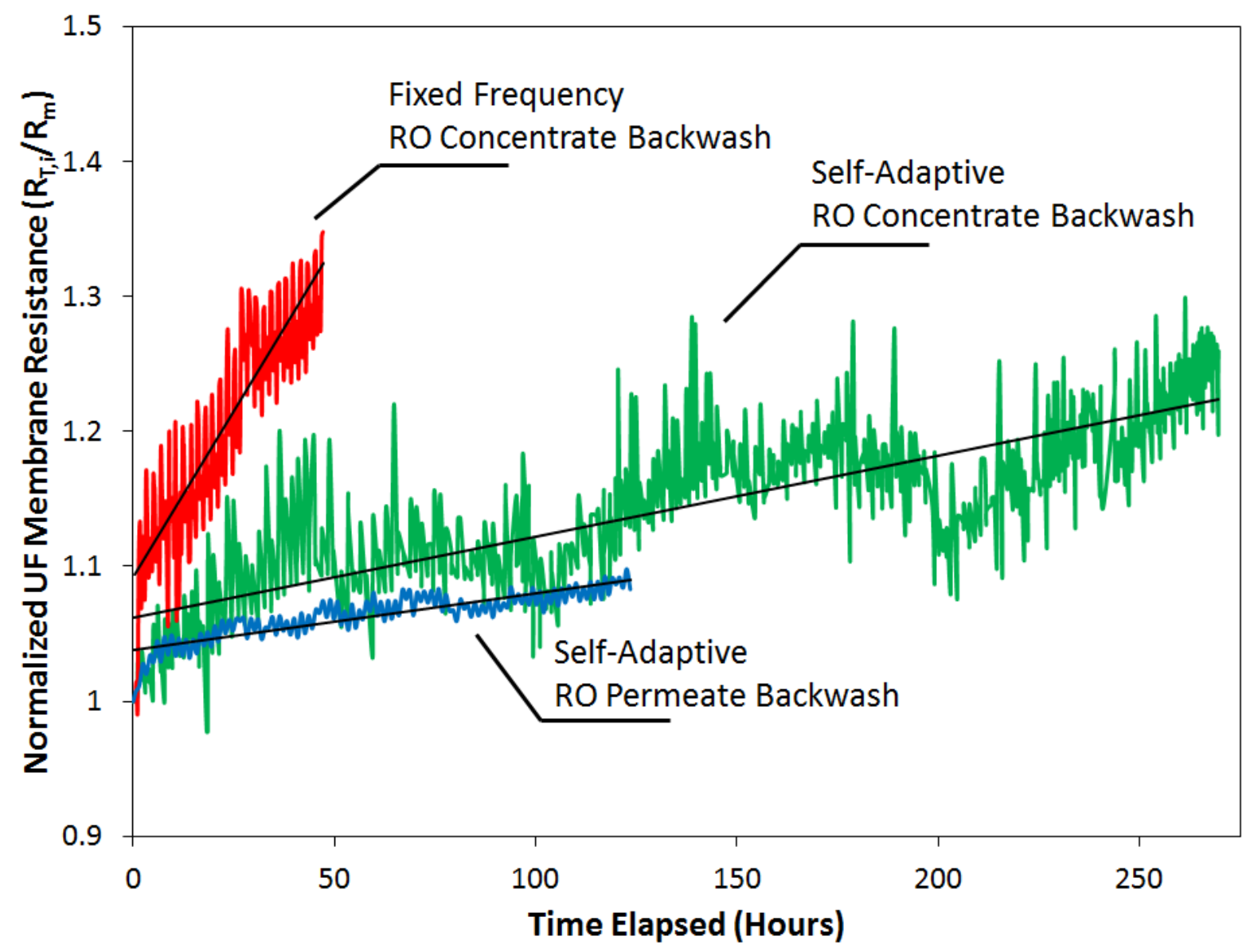

Figure 12. Comparison of the effects of three different UF backwash strategies on the progression of UF resistance (normalized with respect to the initial value) in seawater desalination operation for the integrated-UF-RO system (UF feed flow rate: $4.54 \mathrm{~m}^{3} / \mathrm{h} ; \mathrm{RO}$ recovery: $35 \%)$. 